\title{
AS CARACTERÍSTICAS DA DISCIPLINA TEORIA DA CONTABILIDADE NOS CURSOS DE GRADUAÇÃO EM CIÊNCIAS CONTÁBEIS DAS UNIVERSIDADES DA REGIÃO NORDESTE
}

\author{
THE CHARACTERISTICS OF THE DISCIPLINE THEORY OF ACCOUNTING IN \\ GRADUATION COURSES IN ACCOUNTING SCIENCES AT UNIVERSITIES IN THE \\ NORTHEAST REGION
}

\author{
Florisvaldo Cunha Cavalcante Júnior ${ }^{1}$ \\ Instituto Federal do Sertão \\ Pernambucano - IFSERTÃO-PE \\ junior.ccavalcante@yahoo.com.br
}

\author{
Carla Renata Silva Leitão \\ Universidade Federal Rural de \\ Pernambuco - UFRPE \\ carla.leitao@ufrpe.br
}

\section{Herrisson Queiroz Neto}

Universidade Federal Rural de Pernambuco - UFRPE

queiroz.contabil@hotmail.com

\begin{abstract}
RESUMO
Desde a publicação da Resolução n ${ }^{0}$ 03/1992, do Conselho Federal de Educação, a disciplina Teoria da Contabilidade tornou-se obrigatória nos cursos de Ciências Contábeis de todo o Brasil. Assim, o objetivo deste artigo é investigar as características da disciplina Teoria da Contabilidade nos cursos presenciais, das universidades federais e estaduais da região Nordeste. Sobre os procedimentos metodológicos, estes envolveram pesquisas bibliográfica e documental. Os aspectos analisados foram: o período em que em que a disciplina é ministrada, a carga horária, os pré-requisitos e os principais autores indicados na bibliografia básica. Os dados foram obtidos através de consulta ao Projeto Político Pedagógico (PPP) dos cursos. Espera-se, com esse estudo, que as instituições de ensino, percebam a necessidade de manterem alinhadas e uniformizadas, no tocante as características dos cursos de Ciências Contábeis, sobretudo, na disciplina Teoria da Contabilidade, que foi objeto desse estudo. Acredita-se, que esse estudo vai contribuir para que as instituições tenham uma visão mais ampla, das metodologias que vem sendo adotadas pelas outras instituições, para que elas possam convergir para uma equidade, possibilitando formação igualitária para todos os discentes. Como resultado, a pesquisa revelou que a maioria das instituições $(65 \%)$ adotam a carga horária de 60 horas; prevalece a oferta nos $4^{\circ}$ e $5^{\circ}$ semestres do curso, com $25 \%$ e $35 \%$, respectivamente, e verificou-se que $30 \%$ das instituições não exigem pré-requisito para a disciplina.
\end{abstract}

Palavras-chave: Teoria da Contabilidade. Ensino. Ciências Contábeis.

\footnotetext{
${ }^{1}$ Rua Camilo de Sá, Bloco 6, Apartamento 13, Edificio Jardim Colonial, Petrolina-PE, CEP: 56.480-330.

* Artigo publicado nos anais do I Seminário do Terceiro Setor da UFPE (2017).
} 


\section{ABSTRACT}

Since the publication of Resolution No. 03/1992, of the Federal Council of Education, the discipline Accounting Theory has become mandatory in Accounting courses throughout Brazil. Thus, the objective of this article is to investigate the characteristics of the discipline Accounting Theory in classroom courses, from federal and state universities in the Northeast region. Regarding the methodological procedures, these involved bibliographic and documentary research. The analyzed aspects were: the period in which the discipline is taught, the workload, the prerequisites and the main authors indicated in the basic bibliography. The data were obtained through consultation with the Political Pedagogical Project (PPP) of the courses. It is expected, with this study, that the educational institutions, perceive the need to keep aligned and uniform, regarding the characteristics of the Accounting Sciences Courses, above all, in the discipline Theory of Accounting, which was the object of this study. It is believed that this study will contribute so that the institutions have a broader view, of the methodologies that have been adopted by the other institutions, so that they may be able to converge towards equity, enabling equal education for all students. As a result, the survey revealed that most institutions (65\%) adopt a 60-hour workload; the offer prevails in the 4th and 5 th semesters of the course, with $25 \%$ and $35 \%$, respectively, and it was found that $30 \%$ of the institutions do not require a prerequisite for the discipline.

Keywords: Theory of Accounting. Teaching. Accounting Sciences.

\section{INTRODUÇÃO}

Obrigatória nos cursos de graduação de Ciências Contábeis nas instituições brasileiras, decisão regida pela Resolução n. 03/1992, do Conselho Federal de Educação, a disciplina Teoria da Contabilidade tem sido responsável por diversas mudanças no âmbito dos estudos acadêmicos relacionados a sua área de atuação.

Com a padronização dos procedimentos contábeis sob modelo internacional, através do International Accounting Standards Board (IASB) e do Financial Accounting Standards Board $(F A S B)$, a disciplina Teoria da Contabilidade, cada vez mais, tem se destacado nos cursos de graduação em Ciências Contábeis. Isso tem influenciado a formação de profissionais com um perfil mais científico, incluindo a disciplina Teoria da Contabilidade como área de formação profissional, visto que os conhecimentos teóricos, tais como a história da contabilidade, objetivo da contabilidade, mensuração e reconhecimento de ativos e passivos passam a ser integrados à prática exercida pelos profissionais, fazendo com que estes, ainda na academia, já adquiram capacidade para refletir e questionar as práticas adotadas em determinadas situações (RODRIGUES et al., 2012).

O consenso quanto à harmonização dos padrões contábeis existe em função da "perspectiva de se alcançar melhor comunicação e da possibilidade de contribuir para a redução das diferenças internacionais na divulgação dos relatórios contábeis, ao permitir a comparabilidade das informações" (NIYAMA, 2007, p. 39).

A harmonização das normas contábeis no Brasil implica em um "rompimento da cultura contábil brasileira sobre a forma de contabilizar a valoração dos fatos patrimoniais, ou seja, priorizar a essência sobre a forma" (COSENZA, LOURENCEL, 2011, p. 79).

De acordo com Menezes e Leitão (2016, p. 3), a Resolução de 1992 aponta a uma preocupação evidente com a formação do discente em Ciências Contábeis, indicando a 
necessidade de preparar o futuro contador para "atender às demandas institucionais e sociais, de acordo com as efetivas demandas do desempenho profissional". Embora seja obrigatória nesse processo acadêmico de formação, o órgão regulador não definiu aspectos relevantes da disciplina Teoria da Contabilidade. Como citado por Menezes e Leitão (2016, p. 3), a Resolução n 03/1992 não fazia qualquer recomendação sobre a "grade curricular, disciplinas e respectivas cargas horárias, conteúdo programático e bibliografia, deixando a cargo das IES a responsabilidade de defini-las, desde que atendesse às diretrizes curriculares para o Curso de Graduação em Ciências Contábeis".

Piccoli, Chiarello e Klann (2015, p. 3) argumentam que a disciplina "oferece uma oportunidade ímpar para buscar o criticismo do aluno e de incentivá-lo a expor suas ideias com outros pontos de vista", porque pode ser "definida como um conjunto coerente de princípios hipotéticos, conceituais e pragmáticos que formam um quadro geral de referências para a investigação da natureza da Contabilidade (HENDRIKSEN; VAN BREDA, 1999, p. 32). Nesta concepção, acredita-se que as justificativas para a inclusão da disciplina de Teoria da Contabilidade nos currículos de cursos de Ciências Contábeis se baseiam em desenvolver o ponto de vista crítico dos estudantes sobre a prática contábil e possibilitar que os mesmos sejam capazes de se adaptar e responder melhor às mudanças das práticas de mercado e da atividade profissional (ROSA et al., 2012). Como a Contabilidade passou por mudanças significativas, segundo Araujo, Silva e Rech $(2015$, p. 2), "o ensino e a formação do profissional também foram influenciados por tal fato. Deste modo, a adequação das instituições de ensino e das disciplinas ministradas tem papel fundamental no processo de evolução e acompanhamento das mudanças".

O objetivo desta pesquisa é investigar as características da disciplina Teoria da Contabilidade nos cursos de graduação em Ciências Contábeis na modalidade presencial das universidades estaduais e federais na região Nordeste.

Para alcançar esse objetivo, foram analisados o período em que em que a disciplina Teoria da Contabilidade é ministrada, a carga horária, os pré-requisitos e os principais autores indicados na bibliografia, com base no Projeto Político Pedagógico do curso de Ciências Contábeis de todas as universidades estaduais e federais da região Nordeste.

Diante desse contexto geral de abordagem, esta pesquisa apoia-se na necessidade de se evidenciar as características adotadas na disciplina Teoria da Contabilidade pelas universidades estaduais e federais.

A pesquisa também se torna relevante por trazer discussões e contribuições acerca das características da disciplina Teoria da Contabilidade adotadas pelas IES Estaduais e Federais, corroborando a ideia de que há divergências e a necessidade de padronização. Silva et al. (2017), em seu estudo sobre as relações das disciplinas de Ciências Contábeis da região Sul e Sudeste, sugeriram que futuras pesquisas poderiam realizar a análise em outros estados brasileiros, ou mesmo incluir as universidades federais ou municipais em seu escopo. Outra justificativa para a pesquisa está nos casos de transferência entre cursos. Nesses casos, havendo harmonia entre as ementas, os discentes não ficam prejudicados caso a disciplina já tenha sido ministrada na IES anterior (ARAUJO; SILVA; RECH, 2015).

\section{REVISÃO DA LITERATURA}

\subsection{A TEORIA DA CONTABILIDADE E SEUS OBJETIVOS}

A Contabilidade é a ciência que estuda e controla as variações quantitativas e qualitativas do patrimônio, seu objeto de estudo. Entretanto, sem um embasamento teórico, a 
Contabilidade não terá subsídios para desenvolver sua finalidade. Neste contexto, a Teoria da Contabilidade torna-se uma ferramenta indispensável para o exercício pleno da rotina contábil (IUDÍCIBUS, BEUREN; SANTOS, 2016).

No Brasil, a disciplina de Teoria da Contabilidade foi inserida no currículo do curso de Ciências Contábeis, de forma obrigatória, com a Resolução 03/92 do Conselho Federal de Educação. A referida resolução também aborda que a disciplina é obrigatória na formação específica (BRASIL, 1992).

A disciplina objetiva capacitar o discente a entender o universo contábil de forma ampla e interdisciplinar, pois, além de evidenciar fatos históricos, tem enfoque nas normas, regulamentos, resoluções, princípios, postulados entre outros, com o objetivo de nortear o futuro profissional nas suas condutas cotidianas no competitivo mercado de trabalho. No ponto de vista de Araújo, Silva e Rech (2015, p. 4), a Teoria da Contabilidade é "uma disciplina que tem a função de contribuir com a formação do discente e que o mesmo, posteriormente, contribua com a sociedade [...]".

Acerca da temática, Miranda, Moraes e Nakao (2008, p. 2) expõem que a "Teoria da Contabilidade tem dentre seus principais objetivos estruturar os conhecimentos sobre a contabilidade, de maneira a desenvolver teorias que relacionem os fenômenos econômicos com as possíveis maneiras de interpretação, de comunicação e de explicação para estes eventos".

A disciplina também deve possibilitar ao contador desenvolver a capacidade de analisar situações do cotidiano, propondo soluções dentro de um contorno de princípios e conceitos, que englobam ainda as dimensões normativas da profissão contábil, a eficiência da gestão e o atendimento ao objetivo da contabilidade, que é prover usuários com informações úteis para a tomada de decisão (ROSA et al., 2012).

Soares, Silva e Pfitscher (2011, p. 50), ainda ressaltam que a Teoria da Contabilidade deve permitir ao profissional desenvolver a capacidade de analisar situações do cotidiano propondo soluções dentro de um contorno de princípios e conceitos, que englobam ainda as dimensões normativas da profissão contábil, a eficiência da gestão e o atendimento ao objetivo da contabilidade que é prover usuários com informações úteis para a tomada de decisão.

Iudícibus (2010) afirma que o ensino da Teoria da Contabilidade tem como objetivo, no contexto do curso de Contabilidade, ajudar o aluno a entender não apenas "como fazer", mas "por que é feito assim" ou "se não deveria ser feito diferente", devendo ser capaz de aumentar o poder preditivo, pelo maior entendimento do "porquê" dos que a estudaram. Tais argumentos ratificam a explanação do Conselho Federal de Contabilidade (CFC, 2009), para o qual o objetivo é proporcionar a compreensão dos aspectos teóricos relativos aos critérios de avaliação de ativo, passivo, patrimônio líquido, realização da despesa, compreensão e aplicação dos princípios e das Normas Brasileiras de Contabilidade; proporcionar, ainda, uma visão da evolução histórica do pensamento contábil.

Devido a sua amplitude de conteúdos e os elementos nele contidos, a disciplina Teoria da Contabilidade tem grande relevância no ensino de graduação em Ciências Contábeis, pois proporciona ao profissional uma visão ampla da aplicação dos mecanismos contábeis. Para Miranda, Moraes e Nakao (2008), apresenta relevância ao desenvolver uma abordagem mais profunda ao conteúdo muitas vezes técnico da Contabilidade. Assim, vê-se, na aplicação da disciplina, tanto com base nas antigas diretrizes curriculares, quanto nos mais recentes currículos do profissional contábil, a inegável importância na formação acadêmica do contador.

Essa análise é intensificada em Lima Filho e Bruni (2012, p. 2), por considerarem que o "estudo da Teoria Contábil torna-se importante não apenas para pesquisadores e acadêmicos, 
mas também para aqueles cuja atuação profissional encontra-se relacionada à Contabilidade. A relevância, portanto, consiste no fato de que o arcabouço de sustentação das práticas contábeis encontra-se justamente na Teoria da Contabilidade.

Tal ideia é defendida, também, por Theóphilo et al. (2000, p. 10), que por suas características, "oferece uma oportunidade ímpar para se buscar desenvolver o pensamento crítico do aluno e de incentivá-lo a expor e confrontar suas ideias com outros pontos de vista".

No entendimento de Rosa et al. (2012, p. 19), "a Teoria da Contabilidade apresenta inserção nos principais congressos da área como, o Congresso USP de Controladoria e Contabilidade, o Congresso Brasileiro de Custos, e o Congresso Anpcont, tendo em geral, alcançada certa legitimidade com a inclusão de temas exclusivos para apresentação e discussões da disciplina".

Os argumentos apresentados encontram sustentação no estudo de Piccoli, Chiarello e Klann (2015), segundo o qual, a maioria dos alunos da disciplina Teoria da Contabilidade considera esta importante para o seu aprendizado e para o entendimento das demais disciplinas. Depreende-se assim que, na percepção dos respondentes, há forte relação da disciplina Teoria de Contabilidade com as demais disciplinas cursadas. Nesse contexto, "estudar o perfil das disciplinas ministradas nos cursos de bacharelado em Ciências Contábeis adquire relevância (MENEZES; LEITÃO, 2016, p. 2).

\subsection{ENSINO DA TEORIA DA CONTABILIDADE NO BRASIL}

O ensino da Teoria da Contabilidade no Brasil apresenta características distintas a depender da instituição, da região e de outros fatores. Essa realidade é facilmente identificada quando se realiza uma consulta no Plano Político Pedagógico (PPP) do curso de Ciências Contábeis, que geralmente são publicados nos websites das instituições.

A Resolução nº.003/1992 não estabeleceu conteúdos mínimos à disciplina Teoria da Contabilidade, bem como o estágio do curso em que ela deva ser ministrada. As instituições estabeleceram em suas grades curriculares conteúdos considerados importantes para o futuro profissional, desenvolvidos nos mais variados estágios da graduação (CAMPOS; MACHADO; RECH, 2015, p. 3).

Por esse motivo, é facultado às IES a definição da carga horária, período em que a disciplina será ministrada, bibliografias, pré-requisitos, conteúdo programático, entre outros, o que pode trazer inúmeros prejuízos para os acadêmicos, principalmente quando ocorrer transferência entre instituições. Os estudos dos conteúdos ensinados na disciplina de Teoria da Contabilidade nos cursos de graduação em Ciências Contábeis nas instituições federais brasileiras constataram que as ementas analisadas não seguem um padrão quanto ao conteúdo a ser ministrado, tampouco, quanto ao período no qual é ministrada. Além desses aspectos, os estudos apontam que a carga horária da disciplina e as bibliografias indicadas também não são semelhantes. (SOARES; SILVA; PFITSCHER, 2011; CAMPOS; MACHADO; RECH, 2015).

Sacramento (1998, p. 9) sugere que a disciplina seja dividida em dois momentos. "Inicialmente no $2^{\circ}$ ou $3^{\circ}$ período do curso, um conteúdo que permita o aluno compreender o que seja e para que serve a Teoria da Contabilidade. O segundo conteúdo deveria ser oferecido no último ano do curso com conteúdo que permitisse ao aluno ter uma postura transformadora da realidade sob a ótica da teoria contábil".

O ideal seria disponibilizar a disciplina no fim do curso, segundo Iudícibus e Marion (1999), considerando que os alunos estarão em um momento em que os conceitos práticos já apresentados serão explicados pela teoria. Tal ideia é defendida, também, por Theóphilo et al. (2000, p. 10), que afirmam haver, na disciplina Teoria da Contabilidade, problemas de aceitação 
ao ser inserida nos períodos iniciais do curso, pois, nesse estágio, os alunos não estão amadurecidos o bastante para o necessário aproveitamento do seu conteúdo.

Um ponto que merece destaque é "a inserção do tema Contabilidade Internacional na disciplina de Teoria da Contabilidade, motivados pelas recentes mudanças internacionais e pelo processo de harmonização contábil, cerca de $20 \%$ das ementas abordam este assunto" (MIRANDA; MORAES; NAKAO, 2008, p. 8). Essa inserção é extremamente positiva, em virtude da harmonização, padronização e convergência dos procedimentos contábeis vivenciado nos últimos anos.

Essa linha de raciocínio também é seguida por Madeira, Mendonça e Abreu (2003), quando abordam que o ensino da Teoria da Contabilidade deve aproximar a teoria e a prática, acontecendo de forma mais viva. Possuir o domínio da teoria ajuda a explicar e interpretar a prática de assuntos complexos, desenvolvendo habilidades necessárias para a profissão.

Miranda, Moraes e Nakao (2008, p. 8) observaram que os aspectos mais técnicos da área de contabilidade, "como definições de ativos, passivos, ou mesmo relatórios contábeis são menos explorados, uma vez que existem outras disciplinas com objetivos mais específicos a estes assuntos".

No tocante às referências bibliográficas, constatou-se que as obras de "Hendriksen e Van Breda" são as que estão entre as mais citadas. Além desses, nota-se a predominância de outros três: "Iudícibus" com 86\%, "Sá" com 48\% e "Lopes e Martins" com 43\% (MIRANDA; MORAES; NAKAO, 2008, p. 8).

Devido à sua complexidade, "entende-se que os docentes devem estar adequadamente preparados para transmitir o conteúdo que essa disciplina exige, principalmente no que diz respeito às modificações geradas pelo processo de convergência contábil" (MARASSI; FASOLIN; KLANN, 2013, p. 14).

Sacramento (1998) afirma que a partir do momento que o professor é desconhecedor da possibilidade contábil de explicar e predizer os fenômenos, por não ter visão científica, ele não consegue levar os alunos ao aumento e melhoria do conhecimento e a aprenderem a realizar novas descobertas.

Esses argumentos, só reforçam a importância dessa disciplina para a formação completa do profissional de Ciências Contábeis.

\section{METODOLOGIA}

Quanto aos procedimentos metodológicos, a abordagem do problema se deu sob o método quantitativo. Do ponto de vista de seus objetivos, se caracteriza como descritiva. No que se refere a pesquisa descritiva, Gil (2008, p. 47) afirma que "as pesquisas deste tipo têm como objetivo primordial a descrição das características de determinada população ou fenômeno ou o estabelecimento de relações entre variáveis".

Do ponto de vista dos procedimentos técnicos, foi realizado um levantamento bibliográfico e uma pesquisa documental. A pesquisa bibliográfica foi realizada em periódicos da CAPES, SCIELO, Google Acadêmico, Web of Science, entre outros, objetivando a coleta de trabalhos sobre Teoria da Contabilidade. Já a pesquisa documental, ocorreu através de dados secundários, por meio dos Projetos Pedagógicos dos Cursos de Ciências Contábeis (PPC) das universidades estaduais e federais da região Nordeste, disponíveis nos sites das instituições.

A escolha pelas universidades federais e estaduais ocorreu devido ao método de estudo ser a distância. As instituições públicas, geralmente, são mais transparentes, tornando acessível 
os seus PPCs, o que não se observou nas instituições privadas, em que muitas não divulgam informações desse tipo em seus sites, o que prejudicaria a evolução do estudo.

$\mathrm{Na}$ coleta de dados, foram analisadas as características da disciplina Teoria da Contabilidade, especificamente, a carga horária, período ministrado, pré-requisitos e bibliografia básica utilizada. O universo da pesquisa é de 23 instituições, sendo que a amostra foi composta por 20 instituições, as que oferecem o curso de Ciências Contábeis. Após a coleta dos dados, foram tabuladas as informações e apresentadas em gráficos.

\section{ANÁLISE DE RESULTADOS}

A seguir serão apresentados e analisados os resultados da investigação, no tocante à carga horária, período em que a disciplina é ministrada, pré-requisitos e bibliografia básica utilizada. A Tabela 1 demonstra as 20 instituições de ensino superior de Ciências Contábeis cujas informações estavam disponíveis no site da instituição.

Não foi possível coletar os dados, apenas, da Universidade Estadual Vale do Acaraú (UVA), Universidade Estadual do Piauí (UESPI) e da Universidade Estadual do Maranhão (UEMA), pois estes não se encontravam disponíveis nos sites das instituições no período do estudo.

Tabela 1- Relação de IES federais e estaduais pesquisadas

\begin{tabular}{c|c|c}
\hline ESTADO & INSTITUIÇÃO & SIGLA \\
\hline AL & Universidade Estadual de Alagoas & UNEAL \\
\hline AL & Universidade Federal de Alagoas & UNEB \\
\hline BA & Universidade Estadual do Estado da Bahia & UEFS \\
\hline BA & Universidade Estadual de Feira de Santana & UESB \\
\hline BA & Universidade Estadual do Sudoeste da Bahia & UFBA \\
\hline BA & Universidade Estadual de Santa Cruz & UECE \\
\hline BA & Universidade Federal da Bahia & UFC \\
\hline CE & Universidade Estadual do Ceará & UFCA \\
\hline CE & Universidade Federal do Ceará & UFMA \\
\hline CE & Universidade Federal do Cariri & UEPB \\
\hline MA & Universidade Federal do Maranhão & UFPB \\
\hline PB & Universidade Estadual da Paraíba & UFPE \\
\hline PB & Universidade Federal de Campina Grande & UFPI \\
\hline PB & Universidade Federal da Paraíba & UERN \\
\hline PE & Universidade Federal de Pernambuco & UFERSA \\
\hline PI & Universidade Federal do Piauí & UFRN \\
\hline RN & Universidade Estadual do Rio Grande do Norte & UFS
\end{tabular}

Fonte: Dados da pesquisa (2017).

$\mathrm{Na}$ análise da estrutura curricular das 20 instituições pesquisadas, em relação à carga horária/créditos da disciplina Teoria da Contabilidade, houve uma grande variedade de carga horária, conforme apresentado na Tabela 2. 
Tabela 2 - Carga horária da disciplina Teoria da Contabilidade

\begin{tabular}{c|c|c}
\hline CARGA HORÁRIA & INSTIUIÇÕES & $\%$ \\
\hline $60 \mathrm{~h}$ & $\begin{array}{r}\text { UFAL, UESC, UNEB, UEFS, UECE, UFMA, UFCG, } \\
\text { UFPE, UFPI, UERN, UFERSA, UFRN, UFS }\end{array}$ & $65 \%$ \\
\hline $64 \mathrm{~h}$ & UFC, UFCA & $10 \%$ \\
\hline $68 \mathrm{~h}$ & UFBA & $5 \%$ \\
\hline $75 \mathrm{~h}$ & UESB & $5 \%$ \\
\hline $80 \mathrm{~h}$ & UNEAL & $5 \%$ \\
\hline $120 \mathrm{~h}$ & UEPB, UFPB & $10 \%$ \\
\hline \multicolumn{2}{|c|}{} & $\mathbf{1 0 0 \%}$ \\
\hline
\end{tabular}

Fonte: Dados da pesquisa (2017).

Diante dos dados coletados, constatou-se que a maioria das instituições, ou seja, $65 \%$ delas, trabalha com a carga horária de $60 \mathrm{~h} /$ aulas. Embora a carga horária predominante esteja na faixa de 60h/aula, cabe destacar que outros assuntos afins à disciplina Teoria da Contabilidade são ministrados em outros componentes curriculares, a exemplo das disciplinas Ética e Normas Profissionais, que é ministrada em todas as instituições e História do Pensamento Contábil, que é ministrada, por exemplo, na UFAL, UFERSA e UERN.

No tocante à carga horária, os resultados desta pesquisa corroboram o estudo de Sacramento (2000), que avaliou o ensino da Teoria a Contabilidade no território nacional, a partir da avaliação de 133 IES e concluiu que a carga da disciplina, em sua maioria, foi igual ou maior que 60 horas/aula.

O estudo desenvolvido por Cheibub (2003), que teve os mesmos objetivos, concluiu também que a carga horária média nacional encontrada foi de 66 horas, com desvio de 11 horas. Embora tenha se passado mais de 14 anos, percebe-se que a carga horária da disciplina não teve alteração, considerando a maioria absoluta das instituições pesquisadas estão na faixa de 60 horas. O estudo de Soares, Silva e Pfitscher (2011) também manteve uma distribuição parecida com as pesquisas anteriores: 1 com menos de 60 horas, 21 com 60 horas e 4 com mais de 60 horas.

A UEPB e UFPB são as instituições que apresentam maior discrepância em relação ao total de horas, nestas duas instituições a disciplina é ofertada em dois semestres, totalizando 120h/aula, distanciando da média calculada neste estudo que foi de 77 horas, embora os estudos de Soares, Silva e Pfitscher (2011) e Cunha et al. (2014) defendam esta formatação, ou seja, defendem que a disciplina seja ofertada em dois semestres. A Tabela 3 exemplifica a questão através da média, mediana e moda.

Tabela 3 - Análise Descritiva da carga horária da disciplina Teoria da Contabilidade

\begin{tabular}{l|c|c|c|c|} 
Média & 77,83 & Mediana & 77,50 & Moda
\end{tabular}

Fonte: Dados da pesquisa (2017).

Diante dos dados apresentados, infere-se que há uma semelhança entre as IES analisadas, em relação à carga horária das disciplinas, sendo que a de 60 horas é predominante no estudo, representando 13 instituições.

Ainda em relação a essa situação, vale mencionar o estudo realizado por Sousa et al. (2016), sobre carga horária adequada, com 571 estudantes de IES de todo o Brasil. Os autores verificaram que a percepção de carga horária por parte dos discentes era suficiente para o aprendizado. Pode-se inferir que havendo qualidade da carga horária do curso, satisfazendo o discente, este ficará apto para desenvolver as competências genéricas estabelecidas pela 
literatura. Uma carga horária conduzida de forma inadequada pode impedir os estudantes de se envolverem e compreenderem os assuntos ministrados (RAMSDEN, 1991).

No tocante ao semestre em que a disciplina é ministrada, a Tabela 4 aborda detalhadamente a distribuição.

Tabela 4 - Semestre em que a disciplina Teoria da Contabilidade é ministrada

\begin{tabular}{c|c|c}
\hline PERÍODO /SEMESTRE & INSTIUIÇÕES & $\%$ \\
\hline $1^{\mathbf{o}}$ & UESC, UEPB & $10 \%$ \\
\hline $3^{\mathrm{o}}$ & UNEB, UERN, UFS & $15 \%$ \\
\hline $4^{\mathbf{o}}$ & UFCA, UFCG, UFPB, UFERSA, UFRN & $25 \%$ \\
\hline $5^{\mathrm{o}}$ & UNEAL, UECE, UEFS, UESB, UFBA, UFC, UEPB & $35 \%$ \\
\hline $6^{\circ}$ & UFMA, UFPB, UFPE & $15 \%$ \\
\hline $7^{\circ}$ & UFAL, UFPI & $10 \%$ \\
\hline
\end{tabular}

Fonte: Dados da pesquisa (2017).

No que se refere ao semestre em que a disciplina é ofertada, a maior parte se concentra na metade do curso, $60 \%$, ou seja, entre o $4^{\circ}$ e $5^{\circ}$ semestre. Apenas duas instituições ofertam no primeiro semestre do curso e nenhuma das instituições pesquisadas ministram no $2^{\circ}$ e após o $7^{\circ}$ semestre do curso.

Esse fato se justifica porque a disciplina abrange assuntos que não são adequados a abordagem nos períodos iniciais, da mesma forma, se for ofertada no final do curso, acaba prejudicando o acadêmico, visto que muitos assuntos abordados são importantes para assimilação de conteúdos de disciplinas como Contabilidade Intermediária, Avançada, Societária e Comercial, por exemplo, o que foi abordado na Tabela 5.

Esse entendimento também está de acordo com o estudo de Piccoli, Chiarello, Klann (2015), que concluíram que $83 \%$ dos alunos consideram a disciplina de Teoria da Contabilidade importante para o entendimento das demais disciplinas do curso. Segundo tais autores, constatou-se que a maioria das IES concentram a disciplina no primeiro, terceiro e quarto semestre do curso.

No tocante aos pré-requisitos para cursar a disciplina, a Tabela 5 apresenta o detalhamento com relevantes variações entre as instituições.

Tabela 5 - Pré-requisitos para cursar a disciplina Teoria da Contabilidade

\begin{tabular}{c|c|c}
\hline PRÉ-REQUISITOS & INSTIUIÇÕES & $\%$ \\
\hline Sem exigência de pré-requisito & UESB, UESC, UNEB, UFCA, UEPB, UFPB, & $30 \%$ \\
\hline Contabilidade Básica I e II & UNEAL, UEFS, UERN, UFMA & $20 \%$ \\
\hline Contabilidade Geral I e II & UFS & $5 \%$ \\
\hline I & UFERSA, UFRN & $10 \%$ \\
\hline Contabilidade Comercial e Intermediária & UECE & $5 \%$ \\
\hline Contabilidade Avançada & UFAL, UFBA, UFC, UFPI & $20 \%$ \\
\hline Contabilidade Societária I e II & UFPE & $5 \%$ \\
\hline História do Pensamento Contábil & UFCG & $\mathbf{1 0 0 \%}$ \\
\hline
\end{tabular}

Fonte: Dados da pesquisa (2017).

Aproximadamente, um terço das instituições pesquisadas não exigem pré-requisitos para cursar a disciplina, no caso da UESC e UEPB, não haveria possibilidade de se exigir prérequisito porque o componente curricular é ofertado no primeiro semestre. No entanto, $70 \%$ delas julgam necessário que o discente tenha proficiência em outras disciplinas para se habilitar a cursá-la. 
Essa exigência se justifica pelo fato do aprofundamento teórico da disciplina, sem uma noção dos componentes que alicerçam o universo contábil, a tendência é que o discente não apresente o rendimento esperado na disciplina.

No estudo de Rodrigues (2012), que pesquisou a ementa de 22 IES federais, o autor verificou que $41 \%$ das universidades não exigem pré-requisito para cursar a disciplina Teoria da Contabilidade. Dentre as que exigem, verifica-se que $14 \%$ indicam a disciplina "Contabilidade Avançada" como pré-requisito, confirmando, assim, a necessidade do discente ter tido contato com abordagens práticas para ser apresentado ao conteúdo teórico da Ciência Contábil.

Nesse contexto, percebe-se uma melhora significativa, pois no estudo atual, após cinco anos, demonstra que esse número caiu para $30 \%$, o que é relevante, pois o aprendizado é mais rico quando o discente já teve acesso a outros conteúdos embasadores.

Outra questão relevante a ser abordada é a bibliografia básica adotada pelas instituições. Essa questão está detalhada no Tabela 6, onde consta os autores, obras e as instituições que adotam.

Tabela 6 - Bibliografia básica utilizadas em Teoria da Contabilidade

\begin{tabular}{|c|c|c|c|}
\hline AUTORES & LIVROS & INSTITUIÇÕES & $\%$ \\
\hline $\begin{array}{l}\text { CONSELHO FEDERAL } \\
\text { DE CONTABILIDADE } \\
(\mathrm{CFC})\end{array}$ & $\begin{array}{l}\text { Princípios Fundamentais de } \\
\text { Contabilidade e Normas Brasileiras de } \\
\text { Contabilidade }\end{array}$ & UNEAL & $6 \%$ \\
\hline $\begin{array}{l}\text { CONSELHO FEDERAL } \\
\text { DE CONTABILIDADE } \\
(\mathrm{CFC})\end{array}$ & Pronunciamentos técnicos contábeis & UFCG, UFPB & $12 \%$ \\
\hline $\begin{array}{l}\text { CONSELHO FEDERAL } \\
\text { DE CONTABILIDADE } \\
(\mathrm{CFC})\end{array}$ & $\begin{array}{l}\text { Interpretações e orientações técnicas } \\
\text { contábeis }\end{array}$ & $\begin{array}{l}\text { UFCG, UFPB, } \\
\text { UFPI }\end{array}$ & $18 \%$ \\
\hline DIAS FILHO, J. M. & $\begin{array}{l}\text { Novos delineamentos teóricos em } \\
\text { Contabilidade. In: Estudando Teoria da } \\
\text { Contabilidade }\end{array}$ & UFBA & $6 \%$ \\
\hline DIAS FILHO, J. M. & $\begin{array}{l}\text { Características qualitativas da informação } \\
\text { contábil: o problema da } \\
\text { compreensibilidade à luz da teoria } \\
\text { semiótica e da comunicação }\end{array}$ & UFBA & $6 \%$ \\
\hline $\begin{array}{l}\text { DIAS FILHO, J. M.; } \\
\text { BATISTA, L. H. M. }\end{array}$ & $\begin{array}{l}\text { Abordagens da Pesquisa em } \\
\text { Contabilidade. In: Teoria Avançada da } \\
\text { Contabilidade }\end{array}$ & UFBA & $6 \%$ \\
\hline FILHO, J. F. et al. & Estudando Teoria da Contabilidade & UEPB & $6 \%$ \\
\hline FIPECAFI. & $\begin{array}{l}\text { Manual de contabilidade societária: } \\
\text { aplicável a todas as sociedades de acordo } \\
\text { com as normas internacionais e do } \underline{\text { CPC }}\end{array}$ & UFCG & $6 \%$ \\
\hline FIPECAFI. & $\begin{array}{l}\text { Manual de contabilidade das sociedades } \\
\text { por ações }\end{array}$ & UFPI & $6 \%$ \\
\hline FIPECAFI; & $\begin{array}{l}\text { Ernst \& Young. Manual de normas } \\
\text { internacionais de contabilidade: IFRS } \\
\text { versus normas brasileiras }\end{array}$ & UFCG & $6 \%$ \\
\hline FRANCO, $\mathrm{H}$. & $\begin{array}{l}\text { A evolução dos princípios contábeis no } \\
\text { Brasil }\end{array}$ & UFPI & $6 \%$ \\
\hline $\begin{array}{l}\text { HENDRIKSEN, E. \& } \\
\text { VAN BREDA, M. }\end{array}$ & Teoria da Contabilidade & $\begin{array}{l}\text { UESB, UNEB, } \\
\text { UFBA UFC, } \\
\text { UFMA, UFCG } \\
\text { UFPE, UFRN }\end{array}$ & $47 \%$ \\
\hline
\end{tabular}


Continuação

\begin{tabular}{|c|c|c|c|}
\hline AUTORES & $\begin{array}{l}\text { LIVROS } \\
\end{array}$ & INSTITUIÇÕES & $\%$ \\
\hline $\begin{array}{l}\text { HOPWOOD, A. G. e } \\
\text { MILLER, P. }\end{array}$ & $\begin{array}{l}\text { Accounting as Social and Institutional } \\
\text { Practice }\end{array}$ & UFBA & $6 \%$ \\
\hline IUDÍCIBUS, S. de. & Teoria da Contabilidade & $\begin{array}{l}\text { UNEAL, UESB, } \\
\text { UESC UNEB, } \\
\text { UFBA, UFC } \\
\text { UFCA, UFPI, } \\
\text { UERN, UFERSA }\end{array}$ & $59 \%$ \\
\hline IUDÍCIBUS, S. de. & Introdução à teoria da Contabilidade & UNEAL & $6 \%$ \\
\hline $\begin{array}{l}\text { IUDÍCIBUS, S. de. } \\
\text { LOPES, A. B. }\end{array}$ & Teoria Avançada da Contabilidade & UFMA, UFCG & $12 \%$ \\
\hline $\begin{array}{l}\text { IUDÍCIBUS, S. de.; } \\
\text { MARION, J. C. }\end{array}$ & Introdução à Teoria da Contabilidade & UFPB, UFRN & $12 \%$ \\
\hline $\begin{array}{l}\text { IUDÍCIBUS, S. de; } \\
\text { MARION, J. C. }\end{array}$ & $\begin{array}{l}\text { Introdução à Teoria da Contabilidade } \\
\text { para o nível de graduação }\end{array}$ & $\begin{array}{l}\text { UNEB, UFCA, } \\
\text { UEPB, UFRN }\end{array}$ & $24 \%$ \\
\hline LOPES, A. B. & $\begin{array}{l}\text { A informação contábil e o mercado de } \\
\text { capitais. }\end{array}$ & UFBA & $6 \%$ \\
\hline $\begin{array}{l}\text { LOPES, A. B.; } \\
\text { MARTINS, E. }\end{array}$ & Teoria da Contabilidade & UFC & $6 \%$ \\
\hline $\begin{array}{l}\text { LOPES, A. B.; } \\
\text { MARTINS, E. }\end{array}$ & $\begin{array}{l}\text { Teoria da contabilidade: uma nova } \\
\text { abordagem. }\end{array}$ & UFCA & $6 \%$ \\
\hline LOPES, J; RIBEIRO, F. & Estudando a Teoria da Contabilidade & UFPE & $6 \%$ \\
\hline $\begin{array}{l}\text { MARTINS, E., } \\
\text { IUDÍCIBUS, S., } \\
\text { GELBCKE, E. R. }\end{array}$ & $\begin{array}{l}\text { Manual de Contabilidade das Sociedades } \\
\text { por Ações }\end{array}$ & UESC, UFRN & $12 \%$ \\
\hline $\begin{array}{l}\text { MISSAGIA, L. R.; } \\
\text { VELTER, F. }\end{array}$ & $\begin{array}{l}\text { Manual de contabilidade: teoria e mais de } \\
700 \text { questões }\end{array}$ & UNEB & $6 \%$ \\
\hline RAMALHO, É. dos S. & Introdução à Contabilidade & UEPB & $6 \%$ \\
\hline $\begin{array}{l}\text { RIBEIRO FILHO, J. F.; } \\
\text { LOPES, J.; } \\
\text { PEDERNEIRAS, M. }\end{array}$ & Estudando teoria da contabilidade & UFCA, UFERSA & $12 \%$ \\
\hline SÁ, A. L. de. & Teoria da contabilidade & $\begin{array}{l}\text { UNEAL, UNEB, } \\
\text { UFPI, UERN }\end{array}$ & $24 \%$ \\
\hline $\begin{array}{l}\text { SANTOS, J. L. dos; } \\
\text { SCHMIDT, P.; } \\
\text { FERNANDES, L. A.; } \\
\text { MACHADO, N. P. }\end{array}$ & Teoria da Contabilidade & UESC & $6 \%$ \\
\hline SCHMIDT, $\mathrm{P}$. & História do Pensamento Contábil & UESB & $6 \%$ \\
\hline $\begin{array}{l}\text { SCHMIDT, P.; SANTOS, } \\
\text { J. L. dos. }\end{array}$ & $\begin{array}{l}\text { História da Contabilidade: foco na } \\
\text { evolução das escolas do pensamento } \\
\text { contábil }\end{array}$ & UFAL & $6 \%$ \\
\hline $\begin{array}{l}\text { SCHMIDT, P.; SANTOS, } \\
\text { J. L. dos. }\end{array}$ & $\begin{array}{l}\text { História da contabilidade: foco nos } \\
\text { grandes pensadores }\end{array}$ & UFAL & $6 \%$ \\
\hline $\begin{array}{l}\text { SILVA, C. A. T.; } \\
\text { NIYAMA, J. K.. }\end{array}$ & Teoria da Contabilidade & $\begin{array}{l}\text { UFBA, UFCA, } \\
\text { UFMA, UERN, } \\
\text { UFERSA }\end{array}$ & $29 \%$ \\
\hline $\begin{array}{l}\text { SILVA, A. C. R. da; } \\
\text { MARTINS, W. T. S. }\end{array}$ & $\begin{array}{l}\text { História do pensamento contábil: com } \\
\text { ênfase na história da contabilidade } \\
\text { brasileira. }\end{array}$ & UFAL & $6 \%$ \\
\hline SUNDER, S. & Teoria da Contabilidade e do Controle. & UFCG & $6 \%$ \\
\hline $\begin{array}{l}\text { WATTS, R. L.; } \\
\text { ZIMMERMAN, J. L. }\end{array}$ & Positive Accounting Theory & UFBA & $6 \%$ \\
\hline
\end{tabular}

Fonte: Dados da pesquisa (2017). 
Percebeu-se que a bibliografia adotada pelas instituições é bastante diversificada, entretanto, alguns autores aparecem com uma frequência maior, a exemplo de Iudícibus 59\%; Hendriksen e Van Breda 47\%; Silva e Nyhama 29\%; Iudícibus e Marion 24\% e Sá 24\%.

Os resultados do estudo se assemelham com as conclusões da pesquisa de Araújo, Silva e Rech (2015), que concluíram que os autores mais citados nas fichas das disciplinas das instituições públicas analisadas foram "Iudícibus" com 86\%; "Hendriksen e Van Breda" com $71 \%$; o terceiro lugar é ocupado por "Sá" com 48\%, seguido de "Lopes e Martins" com 43\%. A liderança da utilização do livro de Iudícibus é correspondente ao resultado apresentado pelo estudo de Theóphilo et al. (2000), que destaca Iudícibus como o autor mais adotado na disciplina Teoria da Contabilidade.

Madeira et al. (2003) realizaram um estudo quanto às bibliografias mais utilizadas nos cursos de Ciências Contábeis, especificamente na disciplina Teoria da Contabilidade e identificaram os seguintes livros mais utilizados: Sérgio de Iudícibus, Teoria da Contabilidade (71\%); Sérgio de Iudícibus e José Carlos Marion, Introdução à Teoria da Contabilidade (50\%) e Hendriksen e Van Breda, Teoria da Contabilidade (50\%).

Embora a pesquisa de Madeira et al. (2003) tenha sido realizada há mais de dez anos, percebe-se que as obras preferenciais continuam sendo as mesmas, com exceção da obra de Silva e Nyhama que neste estudo ocupa o terceiro lugar com 29\%, embora muito próximo de Sá com 24\%. O que mais chama a atenção é a queda da preferência pela obra da FIPECAFI, onde apenas uma instituição incluiu em sua bibliografia básica.

Vale ressaltar que ficaram inacessíveis as referências adotadas pelas UEFS, UFS e UECE, em virtude de não divulgarem em seus sites. Por isso, essa análise bibliográfica foi baseada em dados de 17 instituições de ensino federais e estaduais.

\section{CONCLUSÃO}

O propósito desta pesquisa foi investigar as características da disciplina Teoria da Contabilidade nos cursos de graduação em Ciências Contábeis na modalidade presencial das universidades estaduais e federais na região Nordeste. Para alcançar esse objetivo, foi analisado o PPC de cursos de graduação em Ciências Contábeis de 20 IES, em universo de 23 instituições, especificamente, dados relacionados a disciplina Teoria da Contabilidade.

A princípio, observou-se que a maioria das instituições, ou seja, 65\%, adota a carga horária de $60 \mathrm{~h}$, embora duas instituições apresentem uma carga horária distante da moda, $120 \mathrm{~h}$. Chegou-se à conclusão de que a carga horária média da disciplina é aproximadamente $78 \mathrm{~h}$. Vale ressaltar que há outras disciplinas que abordam conteúdos afins a Teoria da Contabilidade, por exemplo, História do Pensamento Contábil, que é ministrada, por exemplo, na UFAL, UFERSA e UERN.

Em relação ao período em que a disciplina é ofertada, observou-se que a preferência das instituições prevalece os $4^{\circ}$ e $5^{\circ}$ semestres do curso, com $25 \%$ e $35 \%$ respectivamente. Os achados corroboram os resultados das pesquisas de Piccoli, Chiarello, Klann (2015) e Theóphilo et al. (2000), que defendem que a disciplina não deve ser ofertada no início do curso. Apenas duas instituições ofertam no primeiro semestre e nenhuma das instituições pesquisadas ministram no $2^{\circ}$ e após o $7^{\circ}$ semestre.

No que se refere aos pré-requisitos, verificou-se que $30 \%$ das instituições não exigem. As demais instituições exigem pré-requisitos de disciplinas importantes e específicas do curso, a exemplo de Contabilidade Avançada, Intermediária e Societária. Observou-se também que algumas instituições ofertam Teoria da Contabilidade II como disciplina eletiva, como é o caso 
da UERN. Entende que os pré-requisitos são necessários para cursar esta disciplina, pois há a necessidade do discente ter tido contato com abordagens práticas para ser apresentado ao conteúdo teórico da Ciência Contábil.

Verificou-se que a bibliografia básica utilizada, embora bastante diversificada, ainda há quase as mesmas preferências de cerca de 15 anos atrás. $O$ fato foi constatado através do confronto com as pesquisas de Theóphilo et al. (2000) e Madeira et al. (2003). Iudícibus; Hendriksen e Van Breda; Iudícibus e Marion e Sá, ainda continuam como os mais abordados. A exceção foi a inclusão de Silva e Nyhama entre os cinco mais citados e a FIPECAFI que não está mais entre os cinco.

A contribuição desse estudo se concentra no fato de contribuir para a disseminação da importância dessa disciplina no curso de Contabilidade, bem como, da relevância de se padronizar os processos entre as instituições, para que tenhamos profissionais com formação acadêmica sem disparidade.

Portanto, conclui-se que não há uma uniformidade entre as características da disciplina Teoria da Contabilidade, ofertada pelas IES estaduais e federais da região Nordeste. As limitações deste estudo residem no fato de não terem sido analisados todos os PPC das universidades de diferentes regiões do Brasil. Por isso, sugere-se que pesquisas futuras abordem a questão em outras regiões do país, considerando que após a Restruturação das Universidades Federais (REUNI), diversos novos cursos de Ciências Contábeis foram abertos.

\section{REFERÊNCIAS}

ARAUJO, T. S.; SILVA, V. R. da; RECH, I. J. Análise dos conteúdos ministrados na disciplina Teoria da Contabilidade em cursos de graduação em Ciências Contábeis de Instituições Públicas de Ensino Superior do Brasil. In: Congresso de Controladoria e Finanças, 6, 2015, Florianópolis. Anais... Santa Catarina: Universidade Federal de Santa Catarina-UFSC, 2015, p. 18.

BRASIL. Resolução CNE/CES 10, de 16 de dezembro de 2004. Institui as Diretrizes Curriculares Nacionais para o Curso de Graduação em Ciências Contábeis, bacharelado, e dá outras providências.

BRASIL. Resolução n 3, de 5 de outubro de 1992. Fixa os mínimos de conteúdo e duração do curso de graduação em Ciências Contábeis. Conselho Federal de Educação. Brasília, DF, s. 1, p. 15, 2004.

CAMPOS, L. C.; MACHADO, T. R. B.; RECH, I. J. O Ensino da Teoria da Contabilidade em cursos de Graduação e em Cursos de Pós-Graduação Stricto Sensu no Brasil. In: Congresso UFU de Contabilidade, 1, 2015. Uberlândia. Anais... Minas Gerais: Universidade Federal de Uberlândia-UFU, 2015, p. 1-13.

CHEIBUB, T. P. Currículos plenos dos cursos de graduação em Ciências Contábeis: uma análise de grades curriculares recentes. 2003. 206 f. Dissertação (Mestrado em Ciências Contábeis) - Programa Multiinstitucional e lnter-Regional de Pós-Graduação em Ciências Contábeis da UnB, UFPB, UFPE e UFRN, Brasília, DF, 2003. 
CONSELHO FEDERAL DE CONTABILIDADE - CFC. Proposta nacional de conteúdo para o curso de Graduação em Ciências Contábeis - 2a . edição revista e atualizada, 2009.

CONSELHO NACIONAL DE EDUCAÇÃO. Câmara de Educação Superior. Resolução CNE/CES 10, de 16 de dezembro de 2004. Institui as Diretrizes Curriculares Nacionais para o Curso de Graduação em Ciências Contábeis, bacharelado, e dá outras providências. Brasília: Ministério da Educação, dez. 2004.

COSENZA, J. P.; LAURENCEL, L. C. Um olhar sobre a harmonização contábil no Brasil à luz da Teoria Habermasiana. Revista de Informação Contábil. v. 13, n. 4, 2019.

CUNHA, L. C.; BORGERT, A.; RICHARTZ, F.; SOUZA, F. R. A disciplina Teoria da Contabilidade em cursos de graduação: percepção de alunos e professores. Revista GUAL, Florianópolis, v. 10, n. 3, p. 182-203, setembro 2017.

GIL, A. C. Métodos e técnicas de pesquisa social. 6. ed. São Paulo: Atlas, 2008.

HENDRIKSEN, E. S.; VAN BREDA, M. F. Teoria da Contabilidade. 5. ed. São Paulo: Atlas, 1999.

IUDÍCIBUS, S. de. Teoria da Contabilidade. 10 ed. São Paulo: Atlas, 2010.

IUDÍCIBUS, S.; BEUREN, I. M.; SANTOS, V. D. Ensino da Teoria da Contabilidade nos Programas de Pós-graduação de Ciências Contábeis do Brasil. Revista Universo Contábil, v. 12, n. 4, p. 6-29, 2016.

IUDÍCIBUS, S. de; MARION, J. C. Introdução à Teoria da Contabilidade. São Paulo: Atlas, 1999.

LIMA FILHO, R. N.; BRUNI, A. L. Percepção dos graduandos em Ciências Contábeis de Salvador (BA) sobre os conceitos relevantes da Teoria da Contabilidade. REPeC - Revista de Educação e Pesquisa em Contabilidade, ISSN 1981-8610, Brasília, v. 6, n. 2, art. 5, p. 187-203, abr./jun. 2012.

MADEIRA, G. J.; MENDONÇA, K. F. C.; ABREU, S. M. A disciplina Teoria da Contabilidade nos exames de suficiência e provão. Contabilidade Vista \& Revista, Belo Horizonte, ed. especial, p. 103-122, nov. 2003.

MARASSI, R. B.; FASOLIN, L. B.; KLANN, R. C. O ensino de Teoria da Contabilidade no Brasil após o processo de convergência contábil internacional. Contabilidade Vista \& Revista, v. 29 n. 2, 2018.

MENEZES, H. A.; LEITÃO, C. R. S. Características da disciplina de orçamento nos cursos de Ciências Contábeis: um estudo nas Universidades Federais Brasileiras. In: Seminário UFPE de Contabilidade, 5, 2016, Recife. Anais...Pernambuco: Universidade Federal de Pernambuco - UFRPE, 2016, p. 1-13. 
MIRANDA, C. S.; MORAES, M. B. C. NAKAO, S. H. O ensino da Teoria da Contabilidade: uma avaliação em instituições no Estado de São Paulo. In: Encontro da ANPAD, 32.; 2008, Rio de Janeiro. Anais...Rio de Janeiro: Associação Nacional de Pesquisa e Pós-Graduação ANPAD, 2008, p. 1-10.

NIYAMA, J. K. Contabilidade Internacional. São Paulo: Atlas, 2007.

PICCOLI, M. R.; CHIARELLO, T. C.; KLANN, R. C. A percepção dos acadêmicos sobre conceitos abordados na disciplina de Teoria da Contabilidade. Revista de Gestão, Finanças e Contabilidade, v. 5, n. 1, p. 40-57, 2015.

RAMSDEN, P. A performance indicator of teaching quality in higher education: the course experience questionnaire. Studies in Higher Education, v. 16, 1991, p. 129-150.

REVORÊDO, W. C.; SILVA, E. M. O.; RIBEIRO FILHO, J. F. O ensino da disciplina Teoria da Contabilidade nos cursos de graduação de Ciências Contábeis: um estudo realizado em instituições de ensino superior da região metropolitana do Recife e do município de Caruaru em abril de 2004. In: Congresso Brasileiro de Contabilidade, 17., 2004, Santos. Anais... São Paulo, 2004.

RODRIGUES, M. D. N.; PETER, M. da G. A.; MACHADO, M. V. V.; SALES, E. C. de A. S. Ensino da disciplina Teoria da Contabilidade nos cursos de graduação em Ciências Contábeis das Universidades Federais do Brasil. In: ENANGRAD, 23., 2012. Bento Gonçalves. Anais... Rio Grande do Sul, 2012.

ROSA, F. S. da; SOARES, S. V.; ROSA, V. S. da; LUNKES, R. J.; PFITSCHER, E. D. A identidade da Teoria da Contabilidade: uma análise de aspectos da legitimidade sociopolítica e cognitiva da disciplina no Brasil. RINACE-Revista Iberoamericana sobre Calidad, Eficacia y Cambio en Educación, v. 10, n. 4. ISSN: 1696-4713, 2012.

SACRAMENTO, C. O. J. O ensino de Teoria da Contabilidade no Brasil. Caderno de Estudos, São Paulo, FIPECAFI, v.10, n.18, maio/agosto 1998.

SACRAMENTO, C. O. J. O ensino de Teoria da Contabilidade no Brasil. 2000. Dissertação (Mestrado) - Faculdade de Economia, Administração e Contabilidade da Universidade de São Paulo, São Paulo, 2000.

SILVA, A.; BONFIM, M.; VELOZO, É.; SANTOS JUNIOR, E.; SILVA, F.; MOTTA, A.; LIMA, Á.; SANTOS, R. T. B. Um estudo sobre a relação das disciplinas dos cursos de graduação em Ciências Contábeis com os setores econômicos dos arranjos produtivos locais nas regiões Sul e sudeste do Brasil. Revista Polêmica, 2017.

SOARES, V. S.; SILVA, G. R.; PFITSCHER, E. D. Teoria da Contabilidade: o que se ensina nos cursos de Ciências Contábeis das Universidades Federais Brasileiras? Revista de Contabilidade da UFBA, Salvador, v. 5, n. 3, p. 45-57, set./dez., 2011. 
SOUSA, W. D.; NOSSA, V.; NASCIMENTO, J. C. H. B; TEIXEIRA, A. M. C. Avaliação do Ensino Superior em Ciências Contábeis: validação do course experience questionnaire (CEQ) no Contexto Brasileiro. Revista Enfoque, v. 36, p. 59, 2017.

THEÓPHILO, C. R.; SACRAMENTO, C. O. J; NEVES, I. F.; SOUZA, P. L. O ensino da Teoria da Contabilidade no Brasil. Contabilidade Vista \& Revista, vol. 11, n. 3, p. 3-10, dez. 2000. 